\title{
Universals and the Methodenstreit: a Re-examination of Carl Menger's Conception of Economics as an Exact Science
}

\section{Uskali Mäki*}

\section{Introduction}

1. In the latter half of the 19th century, economic thought in the Germanspeaking world was dominated, both intellectually and academically, by the so-called historical school, from Wilhelm Roscher to Gustav Schmoller and others. In 1871, the Austrian Carl Menger published his Grundsätze der Volkswirtschaftslehre (Menger, 1976 (1871)), customarily referred to as one of the three simultaneous discoveries of marginalist economics - the other two marginalist 'revolutionaries' being Jevons in England and Walras in France.' Twelve years later, in 1883, Menger published a major methodological treatise entitled Untersuchungen über die Methode der Socialwissenschaften und der Politischen Oekonomie insbesondere (Menger, 1963 (1883)). This book included criticisms of some of the historicist principles of doing economics. In the same year, Schmoller, leader of the German historicists, wrote a critical review of Menger's book (Schmoller, 1883). Menger reacted forcefully with a more straightforwardly polemical small book, Die Irrthümer des Historismus in der deutschen Nationalökonomie (Menger, 1884). Commentaries by others appeared in later years, but this brief episode amounted to what has thereafter been called the Methodenstreit between Menger and Schmoller. It has been established as perhaps the most famous methodological controversy in the history of the social sciences.

*Department of Philosophy, Erasmus University Rotterdam, P.O. Box 1738, 3000 DR Rotterdam, The Netherlands.

Received 21 July 1993; in revised form 15 April 1996.

${ }^{1}$ Menger's book launched a tradition in economics known as Austrian economics, separate from the dominant Walrasian tradition. In the last 20 years or so, the Austrian tradition has gone through a resurgence especially in the U.S. Among Menger's contemporaries were Friedrich Wieser and Eugen Böhm-Bawerk. I ater generations, typically adopting a more unambiguous free-market orientation, have included, among others, Ludwig von Mises, Friedrich Hayek and Israel Kirzner. 
2. Even if recognized as a major controversy, I believe the positions of the antagonists in the $1880 \mathrm{~s}$ debate on method have not been satisfactorily understood by later generations. The standard perception of the controversy is in terms of an inductive, realistic, empirical, historical, holistic and ethical approach held by Schmoller vs a deductive, abstract, theoretical, aprioristic and individualistic approach espoused by Menger. This popular view lacks accuracy and clarity in details, it oversimplifies and overhomogenizes, and it is therefore misleading much of the time. Part of the reason for this is, of course, the ambiguity found in the original texts. ${ }^{2}$

By focusing on one issue, namely that of universals and how they are dealt with by one party in the controversy, namely Menger, I hope to shed some new light on some aspects of the confrontation. I believe that some of the above oppositions misconstrue the debate. In particular, it will be shown that a theory can be abstract and realistic at the same time; that Menger's approach is not aprioristic in the conventional sense; and that an economics does not have to be inductive in the sense of being based on enumerative induction in order to be empirical. In order to substantiate such suggestions, I adopt the perspective of an essentialist realism of an Aristotelean type when reading Menger's writings. Menger's foremost concern, as opposed to the historicist insistence on grounding all theory on detailed empirical information, was to defend the possibility of a relatively autonomous theoretical economics. He tried to accomplish this by suggesting that theoretical economics is an exact science, involving what he called exact types and exact laws. It is this notion of economics as an exact science that I want to clarify. ${ }^{3}$

3. The philosophical foundations of Menger's economics have been interpreted in a number of ways, including Kantian and Popperian readings. ${ }^{4}$ The Aristotelean interpretation appears to be the most popular, however. Given that Continental social theorists at the time of Menger were typically attracted to neo-Kantian ideas, one might have expected to find ample evidence for classifying Menger as a Kantian. Neo-Kantianism was not, however, the only

${ }^{2}$ On Schmoller, see Lifschitz (1914, pp. 199-253); on both Schmoller and Menger, see Ritzel (1950). There are other questionable simplifications in the popular picture of this period in German-language economic thought. One is the idea that Menger's Gundsätze marked a radical break from German economics; for a challenge of this idea, see Streissler (1990).

${ }^{3}$ The present exercise is part of a larger project in which I attempt to interpret and reconstruct aspects of economic theorizing, including the Austrian approach, in terms of a realist philosophy of science tailored to acknowledging the peculiarities of economics. (See, e.g. Mäki, 1989, 1990a,b, 1991, 1992, 1993, 1994, 1995.)

${ }^{4}$ For a Kantian interpretation, see Dobretsberger (1949). Dobretsberger admits that Menger makes no references to Kant-while there are several to Aristotle-but still argues that Menger subscribes to a Kantian idea that an economic law is a mental imposition, 'an unreal construction of our thinking' ('eine unwirkliche Konstruktion unseres Denkens'; p. 78). It is precisely this idea that will be challenged by the argument of the present paper (while a Kantian reading would be more plausible in the case of Schmoller). For a Popperian reading, see Milford $(1989,1990)$. Interesting as this anachronistic reading is, I am not convinced that it can be carried out without some major distortion of Menger's writings. 
doctrine that had gained wide currency. The intellectual atmosphere in the Austria of those days contained a strong Aristotelean current, not only in the form of popular philosophy, but also inherent in the tradition of social science texts. It can be argued that from his school years onwards it was likely that Menger was exposed to Aristotelean influences to such an extent that he found it unnecessary to document in detail the Aristotelean sources of his views. ${ }^{5}$

The present paper is not an exercise in historical scholarship, trying to put Menger's texts in such historical contexts. It is rather an attempt to provide a systematic reading of his texts--most importantly his Untersuchungen-in largely Aristotelean terms. Earlier or contemporary discussions of Menger's philosophical views from the viewpoint of Aristotelean essentialism include, e.g. Kauder (1957), Bostaph (1978), Smith (1990) (see also Mäki, 1990a,b). However, a detailed and systematic Aristotelean reading of Menger's conception of economics as an exact science is still missing. The novelty of the present paper lies in that, first, it is preoccupied with a detailed interpretation of Menger's 'exact science' view of economics as being based on a realist notion of universals, and that, second, tools utilized for this purpose are partly modern, mostly borrowed from recent scientific realist work on universals and laws (Armstrong, 1978a,b; Dretske, 1977; Tooley, 1977, 1987), whereas the earlier efforts have been more sketchy and have adopted the old Aristotelean perspectives. ${ }^{6}$

4. This paper is an interpretive and reconstructive study in the metaphysical foundations of the economics of Carl Menger. The proposal to be made is simple: what Menger calls exact types in economics can be interpreted as complex universals in the immanent realist sense, and what he calls exact laws are relations between these universals.

This proposal, I believe, makes sense as a plausible interpretation of Menger's unsystematic and sometimes ambiguous statements. The proposal also brings up a badly neglected topic in recent writing on the philosophy of economics in general: the problem of universals. A detailed analysis of the contribution of the major combatant in the most famous methodological debate in the history of economics may provide some tools and inspiration for similar analyses in the context of other traditions and periods in economics.

\footnotetext{
${ }^{5}$ See, e.g. Kauder (1957) and Smith (1986). For very interesting suggested qualifications, see Silverman (1990).

${ }^{6}$ It is notable that in a recent conference on the legacy of Menger, two of the four papers on Menger's methodology did not acknowledge Menger's Aristoteleanism (Milford (1990); Birner (1990); the other two papers are Smith (1990) and Mäki (1990b)). Given what we now understand of Menger's views (which is not very much, after all), I am tentatively inclined to consider such acknowledgement indispensable in any analysis which wishes to retain the authenticity of Menger's own methodology. Of course, the scholarship on Menger may have other legitimate aims as well. Moreover, it has to be acknowledged that none of these interpretations is based on the totality of evidence that is currently available. The unexamined portion of evidence is included in the Carl Menger Papers (notebooks, manuscripts, correspondence) that have recently been made accessible in Duke University's Perkins Library. It will be seen whether interesting revisions will be suggested by examinations of relevant parts of this material.
} 
5. A couple of qualifications are needed to clarify the aim of this paper and to narrow down its focus. Menger (1963)(1883), p. 55) wrote that ' $[t]$ he purpose of the theoretical sciences is understanding of the real world, knowledge of it extending beyond immediate experience, and control of it'. What is here translated as 'knowledge' is what Menger calls Erkenntnis; it is something that makes it possible to predict, to infer from statements about occurrences of particular phenomena to statements concerning other phenomena. Control is based on this kind of predictive knowledge. I will not be concerned with either of these two aims of research in this paper. My concern is closer to Menger's idea of Verständnis, translated above as 'understanding'. This, I am inclined to think, is not to be confused with the hermeneutic Verstehen, since Menger seems to have in mind scientific understanding in a more general sense? This is why I think it would be wiser to relate Menger's idea of understanding to a particular notion of explanation, elaborated in the spirit of some kind of essentialist realism. [I have attempted to do this in Mäki (1990a).] The present paper seeks to clarify the nature of the categories and statements of law that Menger thought would best serve the purpose of explanatory understanding.

6. At this point a further qualification has to be made. It is based on the distinction between theory and its application. This is what Menger obviously had in mind when he wrote in his polemic against the historicists that the theoretical understanding of concrete economic phenomena is especially to be distinguished from the theory of the economy' (Menger, 1963 (1883), p. 45). The relation between the two may be characterized as that of application, 'the theory of the economy' being applied to phenomena in order to understand or explain them, in order to acquire 'theoretical understanding of concrete economic phenomena'. The discussion to follow will be primarily restricted to 'the theory of the economy', its structure and ontological character. Only occasionally will some remarks be made on the application of theory to the explanation of economic phenomena.

7. The structure of the paper is simple. The next section is devoted to a discussion of exact types. The third section is concerned with exact laws. The final section contains some general remarks about economics as an exact science in Menger's sense.

\section{Exact Types as Universals}

1. That the notion of 'type' and particularly the notion of 'exact' or 'strict' type is constitutive of Menger's methodological view becomes evident in the

${ }^{7}$ On this, I disagree with Alter $(1990$, p. 81$)$, who suggests that Verständnis is to be understood as Verstehen in a hermeneutic sense. 
early pages of his Untersuchungen. On the second page of the first chapter he writes as follows:

In spite of the great variety of concrete phenomena, we are able, even with cursory observation, to perceive that not every single phenomenon exhibits a particular empirical form different from that of all others. Experience teaches us, rather, that definite phenomena are repeated now with greater exactitude, now with lesser, and recur in the variation of things. We call these empirical forms types. (Menger, 1963 (1883), p. 36.)

As examples of 'types' Menger (loc. cit.) mentions 'the phenomena of purchase, of money, of supply and demand, of price, of capital, of rate of interest'.

2. The above 'definition' of the concept of type and the subsequent role it plays in his system suggests that Menger formulates his methodological views in terms of the classical problem of universals. Types as the recurring aspects of things are the universals which are exemplified by concrete entities and phenomena, the particulars. To put it in classical terms, a universal is the one, particulars are the many, and consequently economic theory, being concerned with economic types like money and price, is about the one in the many.

It is also noteworthy that Menger thinks of types as forms of phenomena (Erscheinungsformen): forms are the Aristotelean universals. This terminology has some consequences for characterizing Menger's methodology from a comparative perspective. I will return to this point briefly towards the end of the paper.

3. In order to put this idea in richer terms and to get closer to Menger's conception of economics as an exact science, the next move is to introduce his distinction between 'real' types and 'exact' or 'strict' types. This is how he characterizes the difference between the two: While exact types are pure forms of things and phenomena which embody only general features and allow no development, real types are characterized by both general and particular features as well as development (ibid., p. 57). Examples of real types include 'real gold, real oxygen and hydrogen, real water', substances which 'in their full empirical reality' (ibid., p. 58) exemplify such strict types as 'absolutely pure oxygen, pure alcohol, pure gold, a person pursuing only economic aims, etc.' (ibid., p. 61).

Menger's distinction is not as clear as it could be, and his examples fail to help us organize our thoughts about the theoretical categories of economics in any detailed way. Perhaps the following example will illuminate Menger's distinction. Think of money. This particular penny and the cheque book in my pocket now belong to the category of money. They are particular instances of money, they are money tokens. Coins in general, bank notes and cheques in general, and, earlier in history, cattle and shells in general, are to be likewise categorized as money. But they are not money tokens; they may be called generic instances of money. It is these generic instances, I suggest, that Menger had in mind when talking about 'real types'. They embody both the general 
features of money and some of its more specific manifestations (though the individual or unique features of money particulars have been put aside). In addition, these generic instances develop, as the history of money indicates. All this amounts to suggesting a three-fold distinction between universals and their generic and particular exemplifications. ${ }^{8}$

Thus real types are not the true universals. Exact or strict types are. Money in general is one of these universals, exemplified by its particular and generic instances. The money universal has been purified from particularities in the form of which we encounter it in daily life. Consequently, the money universal is not observable in isolation from its particular instantiations, yet it is one of the abstract referents of economics as an 'exact' science.

4. I suggest that insofar as we attempt to understand Menger's position in terms of the problem of universals, we should talk about economic universals. Economic universals involve economizing action on the part of individual agents. Economic price, a person pursuing only economizing activities and the like are among the economic universals in this sense. In contrast, market prices actually paid and businessmen engaged in 'non-economic' activities are not economic universals though they may be economic empirical types.

In his Grundsätze, Menger defined economizing action in terms of scarcity, fullest possible needs satisfaction, perfect information and self-interest. People engage in the activity of economizing if 'the requirements for a good, in the time period over which the provident activity of men is to extend, are greater than the quantity of it available to them for that time period, and if they endeavour to satisfy their needs for it as completely as possible in the given circumstances [...]' (Menger, 1976 (1871), p. 114). Moreover, 'where the available quantity does not suffice for all, every individual will attempt to secure his own requirements as completely as possible to the exclusion of others' (ibid., p. 97). Finally, exact theory presupposes "not only the dogma of ever-constant self-interest, but also the dogma of the "infallibility" and "omniscience" of humans in economic matters' (Menger, 1963 (1883), p. 84).

It is exact economic theory which then 'teaches us to follow and understand in an exact way the manifestations of human self-interest in the efforts of economic humans aimed at the provision of their material needs' (Menger, 1963 (1883), p. 87). However, it 'cannot provide understanding of human phenomena in their totality or of a concrete portion thereof, but it can provide understanding of one of the most important sides of human life [...], the economic' (ibid.; emphasis in the original). Menger goes on by explaining that 'the understanding of the remaining sides of it could only be attained by other theories which would make us aware of the formations of human life from the

\footnotetext{
${ }^{8}$ Milford (1990, pp. 226 227), suggests that Menger's 'real types' are 'individuals' or 'particulars'. My suggestion of a three-fold distinction implies that I find this view mistaken. For an analysis of the metaphysics of money in Menger, see Mäki (1990b).
} 
point of view of the remaining propensities' (ibid.). Among these other 'propensities' he cites 'custom, public spirit, feeling for justice, and love for one's fellow man' as well as 'error' and 'ignorance' (ibid., p. 84). The actual behaviour of people and economies 'in its full empirical reality' manifests these other aspects to a greater or lesser degree. For example, while 'economic prices' only manifest economizing action, actual empirical prices are 'more or less different from the economic' (ibid., p. 71), because they also manifest these other propensities.

5. The rest of this section will be devoted to some questions concerning the sorts and character of exact types understood as universals. Let us begin by asking what kinds of economic universals there are and restrict our brief discussion to three sorts: monadic properties, relations and substances. Among philosophers, monadic properties seem to be the least controversial case, while the status of relations and substances or kinds is more controversial (see, e.g. Armstrong, 1978b; Loux, 1978).

How should Menger's exact types be characterized in relation to these three sorts? The very term 'type' apparently implies that all exact types are kinds or substances, but we should not allow this to mislead us. A price, for instance, though substantial in grammatical form, is a social property of things. Demand, in turn, seems to be a relation between persons and things. Are there economic substances at all in Menger's ontic furniture? Money, for instance, might appear as a promising candidate, but it seems that it can be reduced to a collection of properties (such as the powers to purchase and store value). Thus, we are able to find properties and relations among economic universals, but whether irreducible substances or kinds should also be included will be left as an open question.

6. My next question concerns the character of Menger's economic universals. Are they simple or complex, structured or unstructured? A universal is complex if it has other universals as its parts; otherwise it is simple. A universal is structured if the particulars which have it also have parts which have other universals; otherwise it is unstructured. A structured universal is relationally structured if it includes relations as its parts; otherwise it is non-relationally structured (simple additive aggregates are of this latter sort). [For these notions, see Armstrong (1978b), pp. 67-71.]

It appears that none of the examples of exact types mentioned by Menger is simple. Each of them is complex. It also seems clear that most of them are structured, and relationally so. Think of price and money, the latter as reduced to the property of general purchasing power. They are social properties of things. I have elsewhere (in Mäki, 1990a) suggested that for explanatory purposes, social properties are identified by Menger and later Austrian economists with what they are believed to be, namely with unintended 'invisible-hand' consequences of individual human action (or, in some cases, 
with averages or aggregates of meaningful individual entities). It is easy to see that identification statements of the form

(C) Social entities are unintended consequences of actions by human individuals.

(A) Social entities are aggregates or averages of individual entities, these latter entities being invested with meaning by acting individuals.

purport to provide us with knowledge of the internal genetic structure of economic universals like price and money, very much like identification statements 'Water is a collection of $\mathrm{H}_{2} \mathrm{O}$ molecules' and 'Temperature is mean kinetic energy' reveal the structure of the universals water and temperature. ${ }^{9}$

Are there unstructured complex universals in the ontic furniture of Menger's exact economics? One of his major examples is depicted by 'a person selfinterestedly pursuing the fullest possible satisfaction of his needs' which is best interpreted as (part of) homo oeconomicus. It is this fellow whose action is mentioned above in (C). It is by referring to homo oeconomicus that the internal structure of 'market universals' such as price and money is to be analyzed, but whereas the relational structure of price and money needs to be analyzed, this is less straightforward with respect to homo oeconomicus itself. This latter universal is not to be identified with a system of 'deeper' universals, such as those depicting neurophysiological items. The folk psychological framework of homo oeconomicus is not questioned (cf. Mäki, 1990a,b). Yet, while this is fully obvious in the case of later Austrian economists such as Mises, a qualification is required to understand Menger's position. Menger's theory of goods employs the notions of 'need' and 'human nature' (Menger, 1976 (1871), pp. 52-53), the connection between the two being close: 'Needs arise from our drives and the drives are imbedded in our nature' (ibid., p. 77). ${ }^{10}$ These notions (unlike, say, that of 'preference') provide an open invitation to look for the biological foundations of economizing action. However, Menger himself did not pursue this line much further, and even if he had done so, I suspect he would not have dispensed with all of the intentional contents of the concept of homo oeconomicus: at least part of the intentionality of homo oeconomicus would have been retained.

Now even if homo oeconomicus is not supposed to be identified with a system of 'deeper' universals, this is not to say that it does not have universals as its parts. It does. Self-interest, maximizing and perfect information are all parts of the Mengerian version of homo oeconomicus. Thus, we have here a complex universal. But it is not structured, because those component universalssupposing for the time being that they can be taken as universals-are ${ }^{9}$ This proposal conforms with Armstrong's (1983, p. 139) idea about the proper role of identification in science.

${ }^{10}$ Menger goes on: 'An imperfect satisfaction of needs leads to the stunting of our nature. Failure to satisfy them brings about our destruction. But to satisfy our needs is to live and prosper' (ibid., p. 77). 
attributed to the same particulars, namely human individuals, as homo oeconomicus itself. They are not attributed to universals like price and money, the structure of which they partly constitute; this is why homo oeconomicus is unstructured, unlike price and money which are structured.

7. It is time to introduce a classical issue about universals: do economic universals exist in reality? Or are they rather linguistic or conceptual entities? Realists about universals think that they exist, while nominalists think that only particulars exist. For a realist the one is as real (or even more real) as the many, while for a nominalist at most the many are real. [For an up-to-date discussion of realism and nominalism, see Armstrong (1978a).]

There would seem to be little doubt that Menger may be interpreted as a realist about economic universals. The key quotation is the following:

The phenomena, or certain aspects of them, and not their linguistic image, the concepts, are the object of theoretical research in the field of economics. (Menger, 1963 (1883), p. 37n4; emphasis added.)

Here Menger seems to take an antinominalist position. Exact types, the economic universals as objects of theoretical economics, are really 'out there'.

A terminological point follows immediately from this. Merger draws a contrast between 'exact types' and 'real types', which would seem to imply that exact types are not real. However, this obviously was not his intention. A better name for non-exact types might have been empirical type. In Menger's system of thought, both exact and empirical types seem to be real.

8. In order to illuminate Menger's realism from a comparative perspective, I shall now invite the reader to examine the views of Max Weber and Fritz Machlup briefly.

In his 'Objectivity in Social Science and Social Policy' Weber provides a systematic discussion of his notion of ideal type. He says that ideal types 'cannot be found empirically anywhere in reality' (Weber, 1949, p. 90; emphasis added). This statement also applies to Menger's exact types, which cannot be observed as such; only empirical ('real') types, things and properties 'in their full empirical reality', can. However, while Weber says about an ideal typical concept that it 'is not a description of reality' (loc. cit.), we may claim that this is not the case with the concepts of Menger's exact economic theory; strictly or exactly typical concepts do purport to describe economic universals as parts or aspects of reality. To be more specific, while Weber says that the ideal type 'is a conceptual construct [Gedankenbild] which is neither historical reality nor even a "true" reality' (ibid., p. 93), we might want to say that, in a sense, Menger's concepts depicting exact types seek to display the 'true' reality, namely the universals of economic life.

Furthermore, Weber says of the ideal typical concept that 'it is even less fitted to serve as a scheme under which a real situation or action is to be subsumed 
as one instance. It has the significance of a purely ideal limiting concept with which the real situation or action is compared and surveyed for the explication of certain of its significant components' (ibid., p. 91). Again, in contrast, for Menger real particular situations and actions are instances of exact types understood as economic universals.

That Weber's theory of ideal types is not only nominalist but also instrumentalist is suggested by his statement that ideal types 'are used as conceptual instruments for comparison with and the measurement of reality' (ibid., p. 97) and that 'the construction of abstract ideal-types recommends itself not as an end but as a means' (ibid., p. 92). Thus, while it seems correct to say that Menger's strictly typical concepts have semantic and epistemic content as they stand, Weber's ideal types are relatively empty of such content. Thus, if factual knowledge is the end of theorizing, Menger thinks his exact theory has reached the end (or at least the essential part or aspect of it), whereas Weber's ideal types only serve as means for attaining the end. Of course, the background supposition here is that the end (or the primary end) for Menger is knowledge of universals and for Weber it is knowledge of particulars. Weber's instrumentalism is rooted in his nominalism: he cannot imagine having knowledge of universals since, he thinks, universals do not exist in reality. This is why concepts apparently denoting universals do not do so literally for him: they have only an instrumental function in our theories.

This same spirit is echoed in the more recent writings of the philosophically minded economist Fritz Machlup. The difference is that while Weber attempted to provide an alternative to Menger's notion of exact type, Machlup offers an interpretation of Menger's view. In this interpretation Machlup-incorrectly in my opinion-identifies exact types with Weberian ideal types or says that 'they are close enough' (Machlup, 1978, pp. 173, 231, 255). This identification becomes possible since Machlup, in his characteristically broad-minded manner, glossed over the differences between polarities such as 'empiricaltheoretical, concrete-abstract, given-constructed, reality-fiction, observationidealization, impure-pure', etc. (ibid., p. 193). The suggestion naturally follows that we should discard the 'type' terminology and adopt instead 'operational concept' as equivalent to 'real type' and 'mental construct' as equivalent to 'ideal type' (i.e. 'exact type' in Machlup's opinion) (ibid., pp. 260-261).

Machlup's further remarks that 'the real in the real type is, in my opinion, the set of phenomena visible, audible or tangible to the observer [...]' and that 'the ideal in the ideal type [i.e. exact type] lies in its belonging to the domain of ideas (ibid., pp. 259-260), reveal positivist inclinations: to have real existence is to be observable or 'operational'. In Machlup's view, ideal (i.e. exact) types do not have to do with reality, having more or less fictional and instrumental status. These suggestions are mistaken as an interpretation of Menger's views. 
9. Interpreting Menger as a realist about economic universals is not yet accurate enough. Statements like

[...] pure gold, a person pursuing only economic aims, etc., exist in part only in our ideas (Menger, 1963 (1883), p. 61; emphasis added)

could easily appear to be anomalous from the point of view of my interpretation. To make such statements compatible with the realist interpretation, distinctions have to be made within the realist camp between variants of realism about universals.

It is sufficient for our purposes to distinguish between two variants. Transcendent realism or Platonic realism is the view that universals exist separately, that there is an independent realm of universals ante rem ('before the thing'). This realm is independent both of our concept of it (this is the realist component) and of particular things (this is the transcendent component). A transcendent realist could not say that economic universals 'exist in part only in our ideas'. Thus, Menger is not a Platonist.

Immanent realism denies that universals could exist separately. Instead, universals exist in rebus ('in the thing'); that is, only as instantiated in particular objects. No uninstantiated universals can have real existence. There are universals (this is the realist component), but they exist only as aspects of particular things (this is the immanent component). Universals do not therefore inhabit an independent realm of their own, they rather reside in particulars. This is the traditional Aristotelean view.

It seems clear that Menger is an immanent realist about universals. Let me once more quote the key sentence from Menger: 'The phenomena, or certain aspects of them, and not their linguistic image, the concepts, are the objects of theoretical research in the field of economics' (ibid., p. 37n4; emphasis added). I have already argued that here Menger takes a realist, non-nominalist stance. But the emphasized words indicate that his realism is of the immanent variety. Elsewhere Menger talks about exact social sciences as providing us with 'understanding of a special side of phenomena of human activity' (ibid., p. 62; emphasis added). When discussing the establishment of exact types he says that we do not have to consider 'whether these in reality are present as independent phenomena' (ibid., p. 60).

Consider the examples of homo oeconomicus and economic price. It follows from the immanent realist suggestion that homo oeconomicus does not exist in itself, in the realm of independent economic universals. It may exist only as an aspect of particular human individuals. However, it is not the only aspect. In addition to having the strive for self-interested needs satisfaction, particular empirical individuals may also be driven, as we have seen, by 'custom, public spirit, feeling for justice, and love for one's fellow man' (ibid., p. 84). This is why the complex universal homo oeconomicus is instantiated in individuals only as 
mixed with these other aspects and hence cannot be observed as such. The same applies to economic prices. Actual, particular market prices are instantiations of economic prices (which are manifestations of the activities of economic men), but only in an impure form, intertwined with 'non-economic' influences. Thus economic prices exist only as aspects of particular prices and, consequently cannot be observed as separate entities.

10. The above examples involve a puzzle that deserves a separate brief comment. Recall that economizing action on Menger's view is characterized not only by the absence of 'custom, public spirit, feeling for justice, and love for one's fellow man' (to be studied by exact sciences other than economics) but also by the absence of 'error' and 'ignorance'. Now we cannot say that the economic exact type homo oeconomicus has the universals infallibility and omniscience, while error and ignorance are two other universals within the purview of some other exact theory describing human beings, and that empirical individuals instantiate all these universals. We are reluctant to say of any given particular that it exemplifies both universal $A$ and universal $\neg A$.

Now if infallibility and omniscience were to be regarded as universals, they may well turn out to be uninstantiated universals. This creates a problem to the Aristotelean interpretation, since this interpretation does not comfortably accommodate uninstantiated universals. Menger faces a dilemma. Either the ideal epistemic qualities of infallibility and omniscience are not, after all, to be treated as universals in the immanent realist sense, or homo oeconomicus has to be characterized without invoking them. The first option might lead to adopting the Platonic view: uninstantiated universals can more easily be dealt with from a transcendent perspective (another possibility might be to pursue an interpretation based on the metaphysics of possible worlds; see below, Section 3.9). However - and this provides encouragement to our Aristotelean interpretation-it is the second option that has been prominently adopted in post-Mengerian Austrian economics: in subsequent versions of Austrian theory, economic agents are portrayed as essentially prone to error and ignorance.

11. Let us now turn to the puzzle generated by Menger's statement that economic universals 'exist in part only in our ideas'. The fundamental point is that while economic universals exist in reality they do not exist as separate realities. However, and this is the crucial step, we can think of them separately. We can conceive the universal aspects of things without thinking of particulars in all of their aspects. We abstract from the particularities of things and concentrate on the universals which the particulars exemplify.

This idea is part of the Aristotelean tradition to which Menger seems to belong. He talks about the method of isolation and abstraction, and says that economic universals are 'abstracted from the full empirical reality' (ibid., p. 62). Economic universals do not exist separately but can be thought of separately if 
we abstract them from particulars and isolate them from other universals. It is we who carry out the abstraction and isolation. ${ }^{11}$ This, and this only, seems to be the sense in which universals 'exist in part only in our ideas'. Note the qualification 'in part': universals are brought to our awareness by the cognizant mind by means of the active process of abstraction, but they are not created by the mind. Were they so created, they would exist in our ideas completely, not in part.

Let us briefly return to Machlup's view that exact types are 'mental constructs'. If this were true, exact types would be creations of the economic theorist. To distance Menger's 'abstractive' conception from Machlup's 'constructivist' view, consider the distinction between discovery and invention. We may say that economic universals are discovered by abstraction, whereas 'constructs' are merely more or less useful inventions of the economic theorist. This is one aspect of the debate between realists and instrumentalists. Menger stands on the realist side of the barricade.

\section{Exact Laws as Relations Between Universals}

1. Now that we have some grasp of what Menger may have had in mind when he talked about exact or strict types - they are economic universals understood in the immanent realist sense - our task of clarifying the notion of an exact law will be somewhat easier. The simple idea will be that exact economic laws in Menger's sense are best understood as relations between economic universals. Besides formulating this idea in some detail, the present section will examine some related questions, especially that of necessity in laws.

2. Menger introduces the idea of an exact or strict law by first characterizing a typical relationship hetween particulars:

[...] relationships among concrete phenomena [...] do not exhibit a thorough individuality in every single case. We are able, rather, to observe without much difficulty certain relationships among them recurring now with greater, now with lesser regularity (e.g., regularities in their succession, in their development, in their coexistence), relationships which we call typical. (Menger, 1963 (1883), p. 36.)

As examples of typical relationships Menger mentions 'the regular drop in the price of a commodity as a result of the increase in supply, the rise in the price of a commodity as a result of an increase in currency, the lowering of the rate of interest as a result of considerable accumulation of capital, etc.' (loc. cit.).

3. Analogically with the situation with regard to types, Menger distinguishes two subcategories within typical relationships, both of them called 'laws' (ibid.,

${ }^{11}$ For an account of various aspects and variants of the method of isolation, including its relation to abstraction, see Mäki $(1992,1994)$. Abstraction may be thought of as an operation in 'vertical isolation' whereby universals are isolated from the particular features of the objects that instantiate them. On the other hand, 'horizontal isolation' is an operation whereby things and their properties are isolated from one another at a given level of abstraction. Both operations are extensively used by Menger (which is almost a trivial point; they are ubiquitious in all human thought). 
pp. 50, 57, 59). Empirical laws are recurring relationships between phenomena which exhibit exceptions, whereas exact laws are typical relationships which hold without exception. While empirical laws 'signify merely the actual regularities, determined by way of observation, in the succession and in the coexistence of real phenomena which belong to certain empirical forms' (i.e. to empirical or 'real' types) (ibid., p. 57), exact or strict laws 'which in respect to the approaches to cognition by which we attain to them simply bear within themselves the guarantee of absoluteness' (ibid., p. 59).

To illustrate the distinction, as examples of the two kinds of laws we might think of a statistical demand curve as an exemple of an empirical law, and the theoretical law of demand as an example of an exact law. It is one of Menger's major claims that the method followed by historicist economics-that of diligent data collection and inductive generalization--is, at most, able to attain empirical laws, and that the historicists have failed to understand the radical difference between the two kinds of laws.

4. Although Menger is far from clear about this, it seems that he thinks one basic difference between the two kinds of laws is that while empirical laws connect 'real' or empirical types, exact laws are connections between exact or strict types. If this is the case, then given the proposal that exact types are economic universals, exact laws should be understood as relationships between economic universals. This would make Menger's notion compatible with recent analyses of laws of nature precisely as relations between universals, realistically understood, these analyses having been provided as alternatives to the so-called Humean view of laws (see Armstrong, 1983; Dretske, 1977; Tooley, 1977; Tooley, 1987; Fales, 1990). We now turn to some features of laws suggested by these realist analyses in order to clarify some obscurities and identify some problems in Menger's formulations.

5. Let us begin with the following question: What is the relation of laws as relationships between universals to sequences of, or more generally, relationships between, particular phenomena? What is the relation of the law of demand to particular cases of the positive correlation between a rise in the demand for a good and the decrease in its price? Note that these particular prices and demands have to be instantiations of 'economic prices' and demands by economic men, the universals involved in the law of demand.

Menger might have been ready to accept Armstrong's (1983, pp. 88-92) answer that laws of nature as relations between universals are themselves universals which are instantiated in particular correlations as aspects of these particulars, just as all other universals are instantiated in particulars. And, according to immanent realism, laws as dyadic universals or relations do not have scparate cxistence; they exist only as instantiated in particular relations between particular things. Thus, for instance, the law of demand does not exist independently of its instantiations, but only as a real aspect of 
particular relations between particular prices and demands-these latter being instantiations of economic prices and demands by economic men.

As noted earlier, Menger thinks that besides particular relations there are 'typical relationships' which he divides into empirical and exact laws. Since only the exact laws are genuine universals, we might characterize the other two relationships as generic and particular instantiations thereof (cf. Section 2.3 above): empirical laws are the generic exemplifications, while particular relations are the particular exemplifications of exact laws.

6. The notion of exact laws as relations between economic universals is capable of making excellent sense of the idea of necessitation; this is something that the regularity theory of laws lacks. By briefly examining the idea of necessary connections we can, I think, also make Menger's talk about the 'guarantee of absoluteness' in exact laws, brought about by our 'approach to cognition' (see Section 3.3 above), a little bit more intelligible.

Laws as relations between universals have the form, $N(F, G)$, where $F$ and $G$ are the universals (' $F$-ness' and ' $G$-ness') and $N$ depicts a relation of necessitation between them: $F$-ness necesssitates $G$-ness. Thus, a relation of nomic necessitation holds between universals $F$ and $G$. But it also holds between their particular instantiations: something (which is $F$ ) necessitates something (which is G). (See Armstrong, 1983, pp. 96-97.) Even though the notion of nomic necessitation might be taken as a primitive without much further explication, the idea does have some intuitive appeal. We can think of necessitation as rooted in what the necessitating and necessitated entities are. It is because something is $F$ that it is also $G$. It is because of what it is that it cannot be otherwise.

Let us take $F$ to be an increase in demand and $G$ an increase in price (both demand and price being the 'economic' ones). Both of them can be thought of as properties of particular goods. Necessitation between particular increases in demands and prices holds because these particulars are instances of the universals $F$ and $G$, and necessitation between $F$ and $G$ holds because these economic universals are certain kinds of aggregates or unintended consequences of individual actions (see Section 2.6 above). This is how we might try to understand the law of demand as involving nomic necessitation.

7. There is no doubt that the idea of necessity belongs to Menger's notion of exact laws. Here is some uncontroversial evidence: '[...] strictly typical phenomena of a definite kind must always and, indeed, in consideration of our laws of thinking, simply of necessity, be followed by strictly typical phenomena of just as definite and different type.' (Menger, 1963 (1883), p. 60). Earlier we cited Menger's reference to our 'approaches to cognition by which we attain to' exact laws as guaranteeing 'absoluteness' to those laws. Now he relates necessity to 'our laws of thinking'. 
It seems obvious that necessitation is, in Menger's view, a feature of real relations between universals, and that 'approaches to cognition' and 'laws of thinking' do not primarily define or constitute those relations; rather, they are metaphysically grounded guidelines for thinking about real relations. They might be viewed as ways of finding out the intrinsic necessity and 'absoluteness' of exact laws in the following sense. Provided that economic universals have been correctly isolated from other universals and abstracted from the flow of particular phenomena and that their internal structure has been correctly analyzed by means of identification statements-i.e. given that we know what the nature of certain items in the domain of economics is-we can infer the laws of their behaviour on the basis of this knowledge by obeying certain uncontroversial 'laws of thinking'. The metaphysical point is that given the nature of things, they necessarily behave in the way determined by this nature. The epistemological point is that given our knowledge of the nature of things we can, by applying the 'laws of thinking', infer knowledge of the 'absolute' laws of their behaviour.

8. On the basis of the preceding discussion I can now put my view of the issue of apriorism in Menger's methodology in simple terms. ${ }^{12}$ First, $I$ take apriorism to be an epistemological doctrine. Second, Menger was not an apriorist about acquiring knowledge of exact types, since this knowledge, in his view, is to be abstracted from experience. Third, it is much more plausible to view Menger as being in a sense an apriorist about exact laws, since knowledge of them is derived from our experience-based abstract knowledge of exact types without any further recourse to experience.

9. The final question about exact laws to be raised is concerned with what Menger meant when he wrote that those laws hold without exception. I will approach this question by borrowing the distinction between 'iron laws' and 'oaken laws' from Armstrong (1983, pp. 147-150). Iron laws 'tell us that, given certain conditions, some further state of affairs is necessitated ' $[. .$.$] no matter$ what further conditions are added. If it is a case of [non-probabilistic] necessitation [...], then the law issues in an exceptionless uniformity (ibid., p. 147). On the other hand, 'if $N(F, G)$ is an oaken law, then all that is entailed is that for all $x$ where interfering conditions are absent, if $x$ is $F$, then $x$ is $G$ (ibid., p. 149). But, as a matter of fact, the relation between $F$ and $G$ typically is interfered with and, consequently, oaken laws do not result in exceptionless uniformities.

It might seem that all alleged economic laws are oaken-the ceteris paribus clause attached to them never holds-and that Menger's claim that exact laws hold without exception is exaggerated. Let us take a closer look at Menger's own discussion of the situation. He gives an example concerning the relation

${ }^{12}$ Here my suggestion seems to diverge from that of Smith (1986), for instance. 
between needs and prices and writes that ' $[t]$ he exact law states that with definite presuppositions an increase in need, definite in measure, must be followed by an increase in prices just as definite in measure' (Menger, 1963 (1883), p. 72). Among the required presuppositions Menger mentions, as properties characterizing economic agents, egoistic maximization, full relevant information, epistemic certainty and freedom from external force (ibid., p. 71). He goes on to make the self-evident admission that the above presuppositions in real economy all hold only in rare cases and that therefore as a rule real prices deviate more or less from economic ones'. The same is put in general terms as follows: [...] the results of exact research [...] are true only with certain presuppositions, with presuppositions which in reality do not always apply' (ibid., p. 69).

There seems to be a problem here. I submit that we have two options in attempting a resolution; either reject or at least modify my reconstructive interpretation of exact types and laws in terms of universals, or reject Menger's claim that exact laws do not, by definition, exhibit any exceptions. I will now briefly discuss these two options.

We could let Menger retain his claim about the exceptionlessness of exact laws if we reinterpreted his view in terms of the metaphysics of possible worlds. On this interpretation, Menger would have postulated a non-actual possible world of Wirtschaftlichkeit where all the presuppositions about the properties of economic agents would be true, without being true in the actual world. In this non-actual world exact laws as manifestations of the activities of economic men would also hold without exception. This interpretation diverges from the one pursued in this paper in that in postulating universals we can remain within the boundaries of the actual world as no need to postulate possibilia arises. The possibilist, non-actualist interpretation also encounters additional problems of filling in the gap between economic theory (concerning a non-actual possible world) and its application (to the actual world).

I am, at least tentatively, in favour of the other option. This means that I recommend we retain our actualist interpretation in terms of universals, and suggest that exact laws are oaken laws and, further, that Menger should not have made his claim of exceptionlessness as a defining feature of exact laws. This revisionist proposal is not as dramatic as it may sound. Nothing would follow from it about the important notion of intrinsic necessitation, since the relationship $N(F, G)$ holds in the case of iron laws as well as oaken laws. The difference is that the uniformity $(x)(F x \supset G x)$ does not hold for oaken laws while it does hold for iron laws. There would also be no reason to be ashamed of economic exact laws, if such things existed: they would be in this respect no worse than Newton's First Law which is an oaken law. 


\section{Economics as an Exact Science}

1. In this brief final section I will summarize my interpretation of Menger's defense of the relative autonomy of theoretical economics, based on his view of economics as an exact science. I begin with a few words about the objects of theoretical economics. According to Menger's conception, economic theory is concerned with exact types and exact laws as universals having real existence as aspects of particular things and relations. The objects of exact theories are best understood as economic universals and their relations, manifesting the economizing activities of people.

2. Exact economic theory is likewise to be understood in a realist manner: exact theory is an allegedly true representation of real economic universals. It is to be noted that Menger later made a distinction between what he called 'morphological' and 'theoretical' sciences (Menger, 1889). On this terminology, morphology is about types, while theory is about their laws. However, this does not perturb the realism presupposed by conceptual representation in that both morphology and theory are about real objects and, one hopes, true of them. We can now see that the abstractness of theory (in the sense that it denotes universals) is compatible with its being realistic. Historicists cannot be permitted the sole claim to realisticness on philosophical grounds.

3. The construction of exact economic theory (or morphology and theory) is a matter of discovery. Exact types are discovered by using abstractive isolation. This is an operation leading to knowledge that is a posteriori with regard to empirical experience. Exact laws in turn are discovered by constructing a theory on the basis of our 'morphological' knowledge of exact types. This is at least partly a matter of intensional inference (as opposed to the ordinary extensional inference of mathematical logic): the theory of exact laws is derived from the conceptual contents of the categories we use to denote exact types. This is an a priori operation.

4. The feature in Menger's methodology which may have caused most anxiety among some commentators is the view that no separate retrospective justification based on empirical evidence is required by him for the acceptance of an exact theory. He seems to think that it is the way theory has been constructed that guarantees its reliability. Unfortunately, although Menger was definite about Schmoller's flaws in questions of the construction and justification of economic theory (see Menger, 1884), he never himself formulated his own view in sufficient detail.

5. Menger's negative view of retrospective empirical testing is related to his conception of particulars as conjunctures of several (sorts of) universals. Each science studics only onc sort of universals; thus, economics is interested only in economic universals. It follows that in order to explain particular social phenomena in detail scientists have to resort to insights from all relevant exact 
social sciences about the universals studied by them (for qualifications, see Mäki, 1990a). It also follows that no knowledge concerning particular phenomcna as such can be used as straightforward evidence for one or another exact theory.

6. Our pursuit of a coherent interpretation of Menger's exact science view of economics has helped illuminate two problematic elements that do not quite fit in the picture. One element is in his economic theory, namely the attribution of infallibility and omniscience to economic actors. Subsequent developments in the tradition that Menger started have revised his theory on this matter. The second problematic element is in his metatheory, namely his claim that exact economic laws hold without exception. We saw that this claim can be rejected without giving up the idea of necessitation characteristic of exact laws understood as universals.

7. Menger's characterization of his economic theory as 'exact' and 'formal' is unusual from the present standpoint, since 'exact' and 'formal' are nowadays taken to mean virtually the opposite of what Menger, with his aversion to mathematics in economics, had in mind. But his usage differed from that of his influential contemporaries, too. Leon Walras's mathematical theory of general economic equilibrium certainly was formal in one sense, but Menger, critical of Walras's theory, thought it was his own non-mathematical theory that was appropriately formal, since it was about a special set of Aristotelean forms, the economic universals. On the other hand, J. S. Mill characterized political economy as an 'inexact' science, because accurate descriptions of particular phenomena could not be derived from its theories (see Hausman, 1981). Menger agreed on the premise of Mill's characterization: economics is able to convey only inexact knowledge about particulars. But he did not agree on its conclusion: he believed that theoretical economics is able to convey exact knowledge about universals.

Acknowledgements-Ancestors of this paper have been presented at the 9th International Congress of Logic, Methodology and Philosophy of Science in Uppsala, August 1991; at the symposium on The Methodology of Carl Menger in London, January 1990; and at the Annual Meeting of the History of Economics Society in New York, June 1986. Thanks for comments on earlier drafts go to Samuel Bostaph, Bruce Caldwell, Daniel Hausman, Israel Kirzner, Mario Rizzo, Barry Smith, Stephen Turner, Lawrence White, and two anonymous referees for this journal.

\section{References}

Alter, M. (1990) Carl Menger and the Origins of Austrian Economics (Boulder: Westview).

Armstrong, D. M. (1978a) Universals and Scientific Realism. Vol. I: Nominalism and Realism (Cambridge University Press).

Armstrong, D. M. (1978b) Universals and Scientific Realism. Vol. II: A Theory of Universals (Cambridge University Press).

Armstrong, D. M. (1983) What Is a Law of Nature? (Cambridge University Press). 
Birner, J. (1990) 'A Roundabout Solution to a Fundamental Problem in Menger's Methodology and Beyond', in Bruce Caldwell (ed.), Carl Menger and His Legacy in Economics. Annual Supplement to History of Political Economy 22, 241-261.

Bostaph, S. (1978) 'The Methodological Debate Between Carl Menger and the German Historicists', Atlantic Economic Journal 6, 3-16.

Dretske, F. (1977) 'Laws of Nature', Philosophy of Science 44, 248-268.

Dobretsberger, J. (1949) 'Zur Methodenlehre C. Mengers und der österreichischen Schule', Zeitschrift für Nationalökonomie 12, 78-89.

Fales, E. (1990) Causation and Universals (London: Routledge).

Hausman, D. (1981) 'John Stuart Mill's Philosophy of Economics', Philosophy of Science 48, 363-385.

Kauder, E. (1957) 'Intellectual and Political Roots of the Older Austrian School', Zeitschrift für Nationalökonomie 17, 411-425.

Lifschitz, F. (1914) Die historische Schule der Wirtschaftswissenschaft (Bern: Stämpfli). Loux, M. (1978) Substance and Attribute. A Study in Ontology (Dordrecht: Reidel).

Machlup, F. (1978) Methodology of Economics and Other Social Sciences (New York: Academic Press).

Mäki, U. (1989) 'On the Problem of Realism in Economics', Ricerche Economiche 43, 176-198. Reprinted in Bruce Caldwell (ed.), The Philosophy and Methodology of Economics (Aldershot: Edward Elgar).

Mäki, U. (1990) 'Scientific Realism and Austrian Explanation', Review of Political Economy 2, 310-344.

Mäki, U. (1990b) 'Mengerian economics in realist perspective', in Bruce Caldwell (ed.), Carl Menger and His Legacy in Economics. Annual Supplement to History of Political Economy 20, 289-310.

Mäki, U. (1991) 'Practical Syllogism, Entrepreneurship, and the Invisible Hand: A Critique of the Analytic Hermeneutics of G. H. von Wright', in Don Lavoie (ed.), Economics and Hermeneutics (London: Routledge), pp. 149-176.

Mäki, U. (1992) 'On the Method of Isolation in Economics', Poznan Studies in the Philosophy of the Sciences and the Humanities 26, 319-354.

Mäki, U. (1993) 'The Market as an Isolated Causal Process: A Metaphysical Ground for Realism', in Bruce Caldwell and Stephan Boehm (eds), Austrian Economics: Tensions and New Developments (Boston: Kluwer), pp. 35-59.

Mäki, U. (1994) 'Isolation, Idealization and Truth in Economics', Poznan Studies in the Philosophy of the Sciences and the Humanities 38, 147-168.

Mäki, U. (1995) 'Scientific Realism and Some Peculiarities of Economics', Boston Studies in the Philosophy of Science 169, 425-445.

Menger, C. (1976 (1871)) Principles of Economics (New York: New York University Press). Translation of Grundsätze der Volkswirtschaftslehre.

Menger, C. (1963 (1883)) Problems of Economics and Sociology (Urbana: University of Illinois Press). Translation of Untersuchungen über die Methode der Socialwissenschaften und der Politischen Oekonomie insbesondere.

Menger, C. (1884) Die Irrthümer des Historismus in der deutschen Nationalökonomie (Wien: Alfred Hölder).

Menger, C. (1889) 'Grundzüge einer Klassifikation der Wirtschaftswissenschaften', Jahrbucher für Nationalökonomie und Statistik 19, 465-496.

Milford, K. (1989) Zu den Lösungsversuchen des Induktionsproblems und des Abgrenzungsproblems bei Carl Menger (Wien: Verlag der Österreichischen Akademie der Wissenschaften).

Milford, K. (1990) 'Menger's Methodology', in Bruce Caldwell (ed.), Carl Menger and His Legacy in Economics. Annual Supplement to History of Political Economy 22, 215-239.

Ritzel, G. (1950) Schmoller versus Menger. Eine Analyse des Methodenstreits im Hinblick auf den Historismus in der Nationaloekonomie. Frankfurt am Main. 
Schmoller, G. (1983) 'Zur Methodologie der Staats- und Socialwissenchaften', Jahrbuch für Gasetzgebung Verwaltung und Volkswirtschaft im Deutschen Reich 7, 975-994.

Silverman, P. (1990) 'The Cameralistic Roots of Menger's Achievement', in Bruce Caldwell (ed.), Carl Menger and His Legacy in Economics. Annual Supplement to History of Political Economy 22, 69-91.

Smith, B. (1986) 'Austrian Economics and Austrian Philosophy', in Wolfgang Grassl and Barry Smith (eds), Austrian Economics: Historical and Philosophical Background, (London: Croom Helm), pp. 1-36.

Smith, B. (1990) 'Aristotle, Menger, Mises: An Essay in the Metaphysics of Economics', in Bruce Caldwell (ed.), Carl Menger and His Legacy in Economics. Annual Supplement to History of Political Economy 22, 263-288.

Streissler, E. W. (1990) 'The Influence of German Economics on the Work of Menger and Marshall', in Bruce Caldwell (ed.), Carl Menger and His Legacy in Economics. Annual Supplement to History of Political Economy 22, 31-68.

Tooley, M. (1977) 'The Nature of Laws', Canadian Journal of Philosophy 7, 667-699

Tooley, M. (1987) Causation. A Realist Approach (Oxford: Clarendon Press).

Weber, M. (1949) Methodology of the Social Sciences, trans. and E. A. Shils and H. A. Finch (eds) (Chicago: Free Press). 